J. AMER. Soc. HorT. SCI. 115(6):1019-1024. 1990.

\title{
Ovule Culture to Obtain Progeny from Hybrid Seedless Bunch Grapes
}

\author{
D.J. Gray, J.A. Mortensen, and CM. Benton \\ Central Florida Research and Education Center, Institute of Food and Agricultural Sciences, \\ University of Florida, 5336 University Avenue, Leesburg, FL 34748
}

R.E. Durham and G.A. Moore

Fruit Crops Department, Institute of Food and Agricultural Sciences, University of Florida, Gainesville, FL 32611

Additional index words. embryo rescue, in ovuloculture, Vitis spp., isozymes

\begin{abstract}
Ovules of seedless bunch grapes (Vitis spp.) fertilized by controlled pollination increased in size during berry development. More ovules cultured 10 days or 60 to 70 days after pollination became brown compared to those cultured at 20 to 40 days. Cultured ovules developed with and without endosperm. Globular to torpedo stage embryos were recovered. More embryos and plants were recovered from ovules cultured at 40 or 60 days than at 10 or 20 days after pollination. Pollen parent significantly affected both embryo and plant recovery at certain sampling times. BA incorporated into medium significantly increased embryo germination percentage. Electrophoretic analysis of glucosephosphate isomerase in progeny showed that $67 \%$ to $88 \%$ were hybrids of controlled crosses. Of four vines that fruited thus far, two were seedless. Seedless progeny had smaller seed traces than either parent. Chemical name used: $\mathrm{N}$-(phenylmethyl) -1H-purin-6-amine (BA).
\end{abstract}

Stenospermic grapevines, from which seedless but otherwise normal fruit develop after fertilization (Stout, 1936), form the germplasm base for breeding new seedless cultivars. Using standard breeding techniques, seedless cultivars can only be used as pollen parents (Olmo, 1936). However, with ovule culture it is now possible to use seedless vines as females (Cain et al., 1983; Emershad and Ramming, 1984; Emershad et al., 1989; Gray et al., 1987; Spiegel-Roy et al., 1985). This approach dramatically increases potential germplasm combinations and allows heretofore impossible crosses between seedless cultivars.

Two methods of embryo culture have been developed. One used liquid culture in which ovules are placed on filter paper supports (Emershad and Ramming, 1984; Emershad et al., 1989); the other employed solidified medium (Spiegel-Roy et al., 1985). Each method has been successfully used for Vitis vinifera. However, there are various regionally adapted seedless cultivars that are hybrids between $V$. vinifera and other native Vitis species (Fisher and Bradt, 1985; Moore, 1983, 1985; Moore and Brown, 1977; Pool et al., 1981, 1977; Reisch et al., 1986) that could be used as maternal parents with the aid of ovule culture. One such hybrid is 'Orlando Seedless', which is the only seedless cultivar resistant to Pierce's disease and adapted to tropical and subtropical climates (Mortensen and Gray, 1987). Use of 'Orlando Seedless' in seedless $x$ seedless crosses should lead to more rapid development of improved seedless cultivars adapted to the southeastern United States and Caribbean region.

A previous study found solid medium culture of 'Orlando Seedless' preferable to culture on liquid medium (Gray et al., 1987). In this report, refinements of the system and development of embryos into plants are described, with emphasis on 'Orlando Seedless' and other seedless hybrid cultivars. Isozyme data to confirm parentage, as well as preliminary notes on field performance of the resulting progeny, are included.

Received for publication 21 July 1989. Florida Agricultural Experiment Station Journal Series no. R-00046. The cost of publishing this paper was defrayed in part by the payment of page charges. Under postal regulations, this paper therefore must be hereby marked advertisement solely to indicate this fact.

\section{Materials and Methods}

Flowers on 4- to 7-year-old vines grown at the Central Florida Research and Education Center, Leesburg, experimental vineyard were emasculated immediately before anthesis and pollinated by placing fresh or stored $(-14 \mathrm{C})$ pollen directly onto stigmas. Some of the 'Thompson Seedless' and 'Flame Seedless' pollen used was kindly provided by D. W. Ramming, USDA/ ARS, Fresno, Calif. Pollen was kept in vials and transferred to flowers via a glass rod. Emasculated and pollinated clusters were encased in paper bags to exclude random pollination and then allowed to develop. Berries were harvested at 10, 20, 30, 40, and 60 days after pollination and surface-disinfested for 5 min in $1.3 \%$ sodium hypochlorite containing a drop of surfactant and rinsed twice in sterile deionized water. Ovules were dissected so as not to damage ovular tissue and then cultured, 20 ovules per $100 \times 15-\mathrm{mm}$ petri dish containing $25 \mathrm{ml}$ of autoclave medium. Culture medium consisted of Nitsch and Nitsch (1969) medium with $1 \mu \mathrm{M}$ gibberellic acid (GA), $10 \mu \mathrm{M}$ indoleacetic acid (IAA), $2 \%$ (w/v) sucrose, $0.8 \%(\mathrm{w} / \mathrm{v})$ TC agar (Hazelton Biologics, Lenexa, Kan.), and $0.2 \%$ (w/v) washed, activated charcoal. Charcoal was omitted for the 10-day postpollination culture date.

Ovules were cultured at $26 \pm 2 \mathrm{C}$ under 16-hr cool-white fluorescent illumination $\left(165 \mu \mathrm{mol} \cdot \mathrm{s}^{-1} \cdot \mathrm{m}^{-2}\right)$ for $12 \pm 1$ week, after which they were dissected and examined for embryos. Embryos were placed on autoclave Murashige and Skoog (1962) (MS) medium containing $3 \%(\mathrm{w} / \mathrm{v})$ sucrose and $0.7 \%(\mathrm{w} / \mathrm{v})$ agar, 10 embryos per $100 \times 15-\mathrm{mm}$ petri dish containing 25 $\mathrm{ml}$ of medium, to induce germination. Groups of five germinated embryos were placed on $80 \mathrm{ml}$ of the same MS medium in GA7 culture vessels (Magenta Corp., Chicago) and maintained under the aforementioned conditions. After $=8$ weeks, resulting plants were placed in potting mix in $25 \times 50-\mathrm{cm}$ flats with sealed clear plastic covers and moved to a greenhouse mist chamber. After new growth was evident, flats were removed from the mist chamber to the greenhouse bench, covers were unsealed, then gradually removed over 2 weeks, and individual plants were placed in l-liter pots. Well-developed potted plants were eventually established in vineyard progeny tests.

The crosses made and their responses are given in Table 1. 
Table 1. Embryo recovery and plants obtained from grape ovules cultured 30 to 60 days after pollination for all seedless $\mathrm{x}$ seedless crosses tested.

\begin{tabular}{|c|c|c|c|c|}
\hline \multirow[b]{2}{*}{ Cross } & \multirow[b]{2}{*}{$\begin{array}{c}\text { No. ovules } \\
\text { cultured }\end{array}$} & \multicolumn{3}{|c|}{ Response/ovule (\%) } \\
\hline & & $\begin{array}{l}\text { Embryos } \\
\text { recovered }\end{array}$ & $\begin{array}{c}\text { Germinated } \\
\text { embryos }\end{array}$ & $\begin{array}{c}\text { Plants } \\
\text { established } \\
\text { in soil }\end{array}$ \\
\hline \multicolumn{5}{|l|}{ Orlando Seedless (OS) } \\
\hline$x$ Self & 510 & 20.8 & 11.4 & 6.7 \\
\hline x Arkansas $1105(\mathrm{AK})$ & 631 & 15.2 & 5.5 & 2.5 \\
\hline x Flame Seedless & 361 & 20.2 & 15.2 & 4.7 \\
\hline x Himrod & 406 & 24.6 & 4.9 & 3.0 \\
\hline x Lakemont (LK) & 352 & 9.1 & 5.4 & 4.5 \\
\hline x Missouri Red \#2 (MR2) & 219 & 16.4 & 4.6 & 4.1 \\
\hline$\times$ Mars & 66 & 19.7 & 10.6 & 6.1 \\
\hline x Remaily & 175 & 30.9 & 4.0 & 0 \\
\hline x Saturn & 199 & $32.7^{\circ}$ & 16.1 & 8.0 \\
\hline x Thompson Seedless (TS) & 137 & 14.6 & 10.9 & 6.6 \\
\hline x Vanessa & 66 & 36.4 & 6.1 & 1.5 \\
\hline$x$ FL DN10-46 & 24 & 33.3 & 33.3 & 0 \\
\hline$\times N Y 45791$ & 427 & 20.6 & 4.9 & 2.8 \\
\hline \multicolumn{5}{|l|}{ Himrod } \\
\hline$x$ Self & 8 & 12.5 & 12.5 & 0 \\
\hline x Orlando Seedless & 77 & 10.4 & 2.6 & 2.6 \\
\hline \multicolumn{5}{|l|}{ Mars } \\
\hline x Orlando Seedless & 337 & 23.7 & 7.7 & 2.1 \\
\hline \multicolumn{5}{|l|}{ Missouri Red \#2 } \\
\hline$x$ Self & 196 & 23.0 & 3.1 & 2.6 \\
\hline x Orlando Seedless & 210 & 25.7 & 16.2 & 14.8 \\
\hline x FL F9-68 & 234 & 15.8 & 6.8 & 4.7 \\
\hline \multicolumn{5}{|l|}{ FL BN7-18 } \\
\hline x Orlando Seedless & 305 & 30.8 & 16.7 & 11.5 \\
\hline$x$ Perlette & 447 & 44.7 & 24.2 & 13.6 \\
\hline \multicolumn{5}{|l|}{ FL CD8-116 (CD) } \\
\hline x Arkansas 1105 & 221 & 30.8 & 29.4 & 2.7 \\
\hline \multicolumn{5}{|l|}{ FL F9-68 } \\
\hline x NY 45791 & 66 & 39.4 & 39.4 & 4.5 \\
\hline \multicolumn{5}{|l|}{ NY 45791} \\
\hline$\times$ Self & 20 & 15.0 & 0 & 0 \\
\hline x Orlando Seedless & 61 & 23.0 & 8.2 & 1.6 \\
\hline Total & 5755 & 23.4 & 11.0 & 4.9 \\
\hline
\end{tabular}

Specific crosses and sample times were used in experiments designed to evaluate treatment effects on the recovery and development of embryos and plants. Treatments that were examined for their effect on embryo and plant recovery included ovule sampling time $(10,20,40$, and 60 days after pollination), four pollenizers crossed with 'Orlando Seedless', and reciprocal crosses between 'Orlando Seedless' and 'Missouri Red No. 2'. The effect of cytokinin on germination was evaluated by placing somatic embryos on medium with or without $1 \mu \mathrm{M}$ BA. Relative vigor of plants obtained from various crosses was compared by rating shoot growth after 2 weeks. Polyembryony was infrequently encountered (Durham et al., 1989); however, for defining effects of test variables on ovules, data analysis was based on recovery of only one embryo per ovule. Each experiment consisted of a factorial arrangement of treatments in a completely random design. Replicates consisted of either single ovules or embryos. Data were analyzed with the Statistical Analysis System using categorical modeling with maximum-likelihood estimates, except for vigor ratings, which employed a general linear model (SAS Institute, Inc., 1985).
Parentage of plants from ovule culture was analyzed electrophoretically using the polymorphic enzyme glucosephosphate isomerase (GPI) (Durham et al., 1989).

\section{Results and Discussion}

\section{Ovule culture}

Mean length of ovules from pollinated berries of 'Orlando Seedless' increased from $0.75 \mathrm{~mm}$ at 10 days after pollination to $2.2,4.8$, and $5.8 \mathrm{~mm}$ at 20,40 , and 60 days, respectively. This increase indicates continuous growth and development of ovules during berry maturation and confirms similar observations for seedless $V$. vinifera where growth was measured by weight increase (Spiegel-Roy et al., 1985). Response of ovules sampled at different times after pollination changed dramatically during culture. Ovules dissected and cultured 10 days after pollination became brown, prompting us to add $0.2 \%(\mathrm{w} / \mathrm{v})$ activated charcoal to subsequent media. About $75 \%$ of ovules cultured 20 days after pollination became green on charcoal-containing 

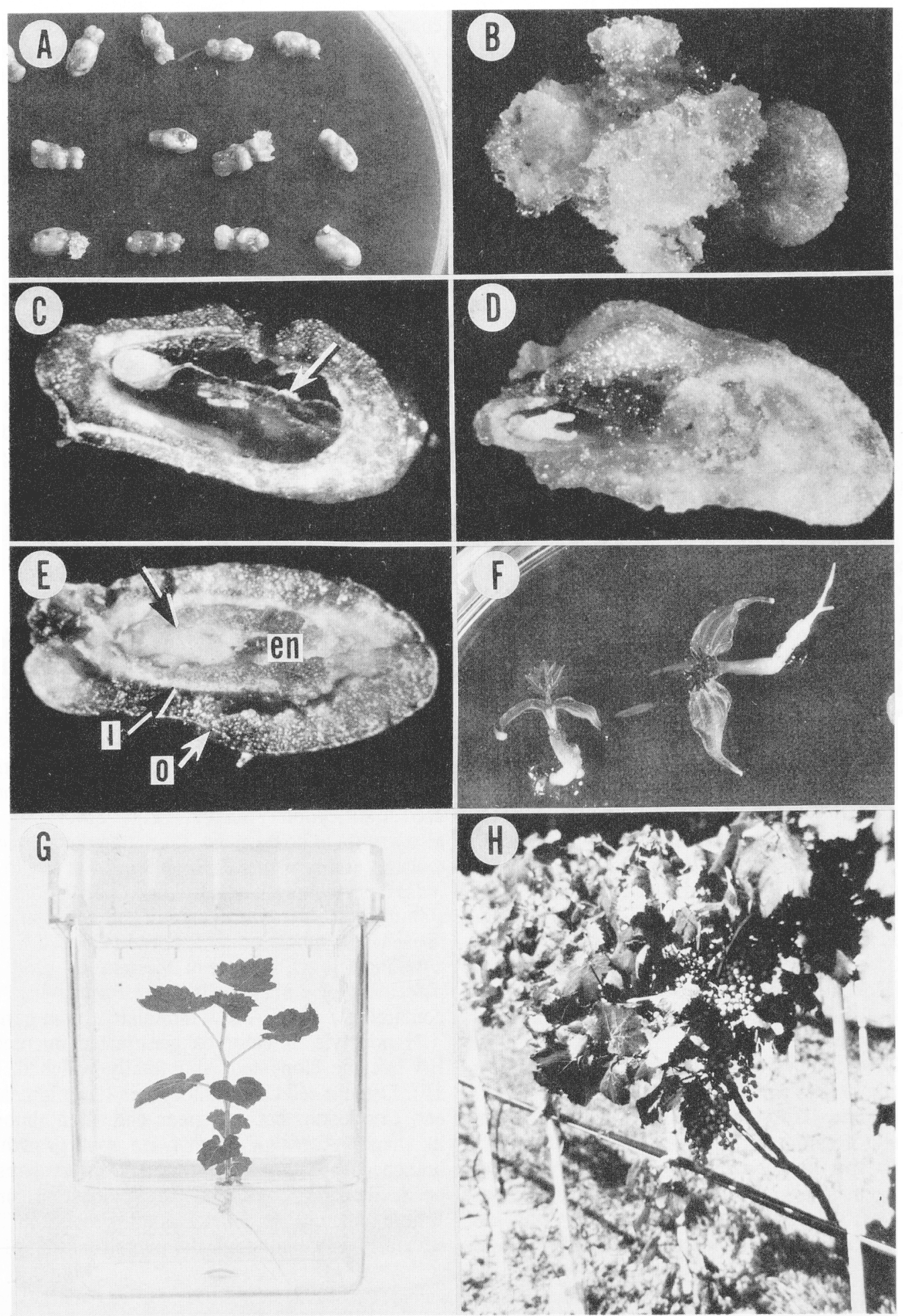

Fig. 1. Grape ovule culture and plant development. (A) Ovules dissected from berries 40 days after pollination $(\times 1.2)$. (B) Callus growth from ovule wall $(\times 9)$. (C) Dissected ovule without endosperm showing globular embryo and collapsed, papery, inner integument (arrow) (×10). (D) Dissected ovule without endosperm containing a torpedo-stage embryo. Note two cotyledons $(\times 10.8)$. (E) Dissected ovule with endosperm (en) and torpedo-stage embryo (arrow). Inner layer of outer integument (I), outer layer of outer integument $(0)(\times 11.7)$. $(\mathbf{F})$ Ovule culture-derived embryos germinating on MS medium with $1 \mu \mathrm{M}$ BA $(\times 1.8)$. $(\mathrm{G})$ Ovule culture-derived plant growing on MS basal medium $(\times 0.68) .(H)$ Ovule culture-derived seedless vine in field $(\times 0.07)$.

medium; we could not determine whether greening was due to sample time, charcoal, or both. Green ovules were larger than brown ovules at 20 days on charcoal-containing medium (data not shown). Most ovules cultured 40 days after pollination be- came green (Fig. 1A) and light-green callus frequently grew from the ovular wall (Fig. 1B). However, progressively more ovules cultured at 60 and 70 days became brown, a change that was correlated with berry softening. It was difficult to remove 
pulp surrounding ovules from softened berries, and the thin layer of remnant pulp appeared to oxidize and cause ovular browning during culture. Thus, the latest developmental stage at which ovules could be conveniently dissected was immediately before berry softening.

Cultured ovules possessed a papery inner integument surrounding endosperm and/or embryos (Fig. 1C). A multilayered outer integument with both a fleshy outer layer and a slightly sclerified inner layer composed the ovule wall (Fig. $1 \mathrm{D}$ and E). This interpretation is consistent with descriptions of integument development for seeded grapes (Pratt, 1971). Abortive ovules appear to be similar to nonabortive ovules with respect to occurrence of multilayered integuments.

\section{Embryo development}

Ovules were dissected and examined for embryos after $12 \pm$ 1 week of culture. Ovules developed both with and without endosperm (compare Fig. 1E with $1 \mathrm{C}$ and D). Embryos were white and situated in the micropyle end of the ovule, with cotyledons protruding inward (Fig. ID). All stages of embryo development, from globular (Fig. 1C) to torpedo (Fig. $1 \mathrm{D}$ and E), were recovered.

Embryos were occasionally found in ovules cultured 10 and 20 days after pollination. After 10 days, a single embryo was obtained from ovules of only one cross, 'Orlando Seedless' $\mathrm{x}$ 'Thompson Seedless' (OS x TS) (Table 2). However, the embryo did not develop into a plant. We could not determine whether or not the absence of charcoal in the 10 day culture medium influenced these results. With culture at 20 days after pollination, $3 \%$ of ovules of 'Orlando Seedless' $\mathrm{x}$ 'Missouri Red No. 2' (OS x MR) and $1 \%$ of OS x TS crosses contained embryos (Table 2). Plant recovery from these crosses was $0 \%$ and $1 \%$, respectively. These results represent the earliest postpollination culture dates from which embryos and plants have been recovered. Previously, $1 \%$ "viable embryos" were recovered from 'Perlette' ovules cultured at 16 days after pollination, but additional details were not provided (Spiegel-Roy et al., 1985). In our study, embryo and plant recovery rates generally increased dramatically at 40 and 60 days postpollination culture dates (Table 2) and plants were eventually obtained from most crosses (Table 1).

For culture of 'Orlando Seedless' ovules with pollen parents listed in Table 3, there was no clear choice between a standardized 40 and 60 days postpollination sampling time when considering recovery of embryos. Similarly, there was no difference between 42- and 70-day sampling periods when measuring embryo enlargement from cultured open-pollinated ovules of 'Thompson Seedless' (Emershad et al., 1989). Currently, we allow berries to develop for up to 60 days, but dissect and culture ovules as early as 40 days if berry softening has commenced. This approach allows the greatest degree of ovular development but also considers ease of dissection.

Comparison of embryo recovery from 'Orlando 'Seedless' with four pollen parents showed 'Orlando Seedless' $x$ 'Lakemont' (OS $\boldsymbol{x}$ LK) produced fewer embryos than other crosses when cultured 60 days after pollination (Table 3). Both OS x LK and OS $x$ TS produced the most embryos at 40 days (Table 3). Reasons for low embryo recovery from OS x LK at 60 days are unknown. There were no statistical differences in embryo recovery at the 60-day culture date between reciprocal crosses and 'seIfs of 'Orlando Seedless' and 'Missouri Red No. 2' (Table $4)$. Differences in recovery of embryos from ovules of reciprocal crosses have not been reported previously, although Cain et al. (1983) showed that pollen parent could significantly affect embryo recovery. Comparison of embryo number from ovules of 'Perlette' selfed and 'Perlette' x 'Flame Seedless' showed no statistical difference (Spiegel-Roy et al., 1985); however, Goldy and Amborn (1987) showed differences in embryo recovery between open-pollinated ovules of several seedless cultivars. It is reasonable to assume that different combining abilities among cultivars would lead to differences in embryo recovery.

\section{Embryo germination}

Embryos from ovule culture germinated poorly when plated onto solidified MS medium with 3\% sucrose. Poor germination was also noted with liquid culture (Emershad and Ramming, 1984). Although a previous report documented germination and growth of plants directly from ruptured ovules (Spiegel-Roy et al., 1985), we found little direct germination in our studies. Grape seeds exhibit dormancy, which is typically alleviated by cold stratification (Flemion, 1937). Embryos from ovule culture also appear to be dormant. Our attempts at cold stratification of isolated embryos at $4 \mathrm{C}$ for 6 weeks failed to promote germination, corroborating previous observations (Emershad and Ramming, 1984). Dormancy of grape somatic embryos can be broken by application of exogenous growth regulators, notably cytokinins (e.g., Gray and Mortensen, 1987). We found that placement of embryos dissected from ovules on MS medium containing $1 \mu \mathrm{M}$ BA also stimulated rapid germination.

Hypocotyls of embryos germinated on medium containing BA became elongated, abnormally widened, and green (Fig. IF). Often a reddish, anthocyanin-like pigmentation was present. Cotyledons became green and often abnormally contorted in shape. Although normal tap root growth was inhibited, branched, possibly adventitious, root systems usually developed. Shoots emerged after the previous postgermination events. Where roots did not develop at all, shoots could be easily rooted adventitiously. Although the overall pattern of growth was ab-

Table 2. Effect of ovule culture date on recovery of embryos and plants from 'Orlando Seedless' (OS) crossed with four pollen parents.

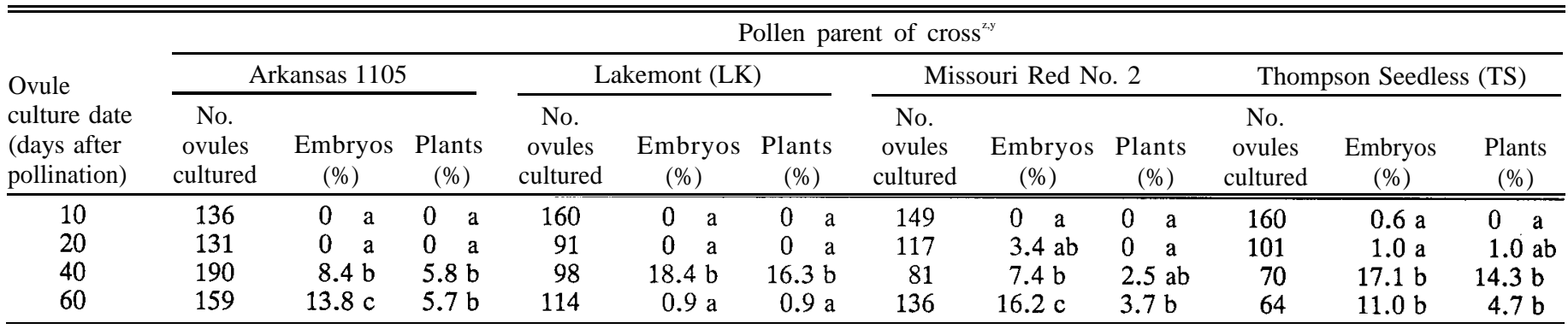

${ }^{2}$ Percentages based on embryos or plants obtained per ovule.

${ }^{y}$ Mean separation within columns by analysis of contrasts from categorical modeling, $P=0.05$. 
Table 3. Effect of pollen parent on recovery of embryos and plants from ovules of 'Orlando Seedless' cultured at two sample times.

\begin{tabular}{|c|c|c|c|c|c|c|}
\hline \multirow[b]{3}{*}{$\begin{array}{l}\text { Pollen } \\
\text { parent }\end{array}$} & \multicolumn{6}{|c|}{ Time after pollination (days) ${ }^{z, y}$} \\
\hline & \multicolumn{3}{|c|}{40} & \multicolumn{3}{|c|}{60} \\
\hline & $\begin{array}{l}\text { No. } \\
\text { ovules } \\
\text { cultured }\end{array}$ & $\begin{array}{c}\text { Embryos } \\
(\%)\end{array}$ & $\begin{array}{l}\text { Plants } \\
(\%)\end{array}$ & $\begin{array}{c}\text { No. } \\
\text { ovules } \\
\text { cultured }\end{array}$ & $\begin{array}{c}\text { Embryos } \\
(\%)\end{array}$ & $\begin{array}{c}\text { Plants } \\
(\%)\end{array}$ \\
\hline Arkansas 1105 & 190 & $8.4 \mathrm{a}$ & $5.8 \mathrm{a}$ & 159 & $13.8 \mathrm{a}$ & $5.7 \mathrm{a}$ \\
\hline Lakemont & 98 & $18.4 \mathrm{~b}$ & $16.3 \mathrm{~b}$ & 114 & $0.9 \mathrm{~b}$ & $0.9 \mathrm{a}$ \\
\hline Missouri Red No. 2 & 81 & $7.4 \mathrm{a}$ & $2.5 \mathrm{a}$ & 136 & $16.2 \mathrm{a}$ & $3.7 \mathrm{a}$ \\
\hline Thompson Seedless & 70 & $17.1 \mathrm{~b}$ & $14.3 \mathrm{~b}$ & 64 & 10.9 a & $4.7 \mathrm{a}$ \\
\hline
\end{tabular}

${ }^{2}$ Percentages based on embryos or plants per ovule.

${ }^{y}$ Mean separation within columns by analysis of contrasts from categorical modeling, $P=0.05$.

Table 4. Effect of reciprocal crosses and selfs on recovery of embryos and plants from ovules sampled at 60 days after pollination. ${ }^{2 . y}$

\begin{tabular}{lccr}
\hline \hline Cross & $\begin{array}{c}\text { No. ovules } \\
\text { cultured }\end{array}$ & $\begin{array}{c}\text { Embryos } \\
(\%)\end{array}$ & $\begin{array}{c}\text { Plants } \\
(\%)\end{array}$ \\
\hline Orlando Seedless (OS) x self & 129 & $20.9 \mathrm{a}$ & $16.3 \mathrm{a}$ \\
OS x Missouri Red No. 2 (MR) & 136 & $16.2 \mathrm{a}$ & $3.7 \mathrm{~b}$ \\
MR x self & 194 & $22.2 \mathrm{a}$ & $2.6 \mathrm{~b}$ \\
MR x OS & 208 & $22.6 \mathrm{a}$ & $14.9 \mathrm{a}$ \\
\hline
\end{tabular}

${ }^{2}$ Percentages based on embryos or plants per ovule.

${ }^{y}$ Mean separation within columns by analysis of contrasts from categorical modeling, $P=0.01$.

Table 5. Interaction of BA and cross on germination of embryos dissected from cultured ovules.

\begin{tabular}{lcc}
\hline \hline Factors & $\begin{array}{c}\text { No. embryos } \\
\text { tested }\end{array}$ & $\begin{array}{c}\text { Germination } \\
(\%)^{2}\end{array}$ \\
\hline BA $(\mu \mathrm{M})$ & 127 & $26.7 \mathrm{a}$ \\
0 & 242 & $47.9 \mathrm{~b}$ \\
1 & & \\
Cross & & \\
Orlando Seedless (OS) & 70 & $54.3 \mathrm{a}$ \\
$\quad \times$ Flame Seedless & 125 & $42.4 \mathrm{ab}$ \\
OS $\times$ NY 45791 & 87 & $34.5 \mathrm{~b}$ \\
Mars X OS & 87 & $33.3 \mathrm{~b}$ \\
FL CD8-116 x Arkansas 1105 & & $* *$ \\
Main effects & & $* *$ \\
BA & & NS \\
Cross & & \\
BA $\times$ cross & & \\
\hline
\end{tabular}

${ }^{2}$ Mean separation by analysis of contrasts from categorical modeling, $P=0.05$.

NS,**Nonsignificant or significant at $P=0.01$, respectively.

normal, BA significantly promoted germination. Nearly twice as many embryos germinated on BA-containing medium when data from four crosses were pooled (Table 5). Embryos from test crosses differed from each other in average combined response, but there was no interaction between cross and BA (Table 5). The stimulative effect of BA was most dramatic for FL CD8-116 x 'Arkansas 1105' (CD x AK), where 46\% germination was obtained with BA compared to $7 \%$ without (Fig. 2). Emershad and Ramming (1984) did not obtain germination in embryos from liquid medium using gibberellic acid and the cytokinin N-(3 -methyl-2 -butenyl)- 1H-purin-6-amine (2iP). However, in our previous comparison of liquid and solid medium culture methods, we also obtained poor germination using liquid medium (Gray et al., 1987). Therefore, method of ovule

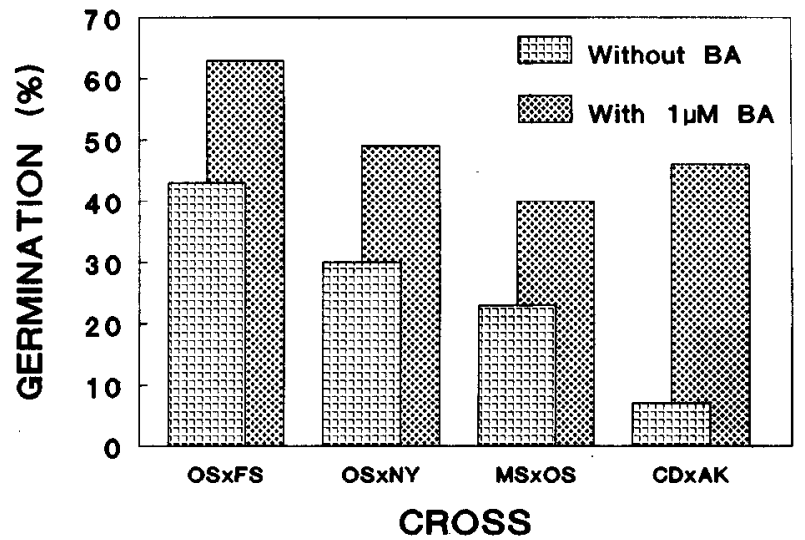

Fig. 2. Effect of BA on germination of ovule culture-derived embryos from four crosses. OS x FS = 'Orlando Seedless' x 'Flame Seedless', OS x NY = 'Orlando Seedless' x NY 45791, MS x OS = 'Missouri Red No. 2' x 'Orlando Seedless', CD x AK = FL CD8116 x 'Arkansas 1105'.

Table 6. Vigor of plants obtained from ovule culture from various crosses.

\begin{tabular}{lcc}
\hline \hline Cross & $\begin{array}{c}\text { No. plants } \\
\text { tested }\end{array}$ & $\begin{array}{c}\text { Vigor } \\
\text { rating }\end{array}$ \\
\hline Orlando Seedless (OS) x Arkansas 1105 & 11 & $1.56 \mathrm{a}$ \\
Missouri Red No. 2 (MR) x FL F9-68 & 16 & $1.0 \mathrm{ab}$ \\
OS x Thompson Seedless & 5 & $1.0 \mathrm{ab}$ \\
MR x OS & 40 & $0.95 \mathrm{ab}$ \\
MR x self & 19 & $0.79 \mathrm{~b}$ \\
OS x self & 27 & $0.78 \mathrm{~b}$ \\
OS x MR & 8 & $0.75 \mathrm{~b}$ \\
OS x Flame Seedless & 8 & $0.63 \mathrm{~b}$
\end{tabular}

${ }^{\text {zVigor of potted plants was subjectively rated after } 2 \text { weeks of shoot }}$ growth on greenhouse benches: $0=0$ to $2 \mathrm{~cm}, 1=2$ to $10 \mathrm{~cm}, 2$ $=$ more than $10 \mathrm{~cm}$.

'Mean separation by Duncan's multiple range test, $P=0.05$.

culture appears to have an effect on subsequent germination response. Because number of days (10-90) that embryos were kept on BA-containing medium had no significant effect on plant recovery (data not shown), we now routinely keep germinated embryos on medium with BA for 4 to 6 weeks.

\section{Plant development}

Germinated embryos (i.e., small plants) transferred to GA7 vessels developed branched root systems and shoots with numerous nodes and leaves (Fig. 1G). After acclimation, plants were established in greenhouse pots, grown for an additional 2 weeks, and then rated for vigor (Table 6). Progeny from OS $\mathrm{x}$ AK were most vigorous. The poor response of selfs denotes inbreeding depression inherent to grape. These results suggest that certain crosses are more likely than others to result in vigorous vines.

As previously described for embryo recovery, efficiency of plant development was related to date of ovule culture. Culture of ovules 40 and 60 days after pollination generally resulted in more plants when compared to earlier dates (Table 2). However, the number of plants recovered was not always proportionate to the number of recovered embryos. For instance, for OS x AK, more embryos were recovered at 40 than at 60 days, but a similar number of plants were obtained at both dates (Table 2). Different pollen parents did not influence plant recovery from 'Orlando Seedless' ovules at the 60-day culture date, but more 
variation in response was evident at 40 days (Table 3). However, comparison of reciprocal crosses and selfs of 'Orlando Seedless' and 'Missouri Red No. 2' cultured at 60 days after pollination showed striking differences in plant recovery due to pollen parent. Here, use of 'Orlando Seedless' pollen resulted in significantly more plants (Table 4).

Differences in embryo and plant recovery between sample times and among crosses show that embryo and plant development are independent events with different response stimuli during ovule culture. Observed responses could be due to many factors; including differences in genetic compatibilities between parental germplasm. However, study of these factors is difficult. For example, a given cross may produce a high frequency of embryos, but few plants will result if the embryos are immature and/or germinate poorly. A similar number of plants would be obtained if the converse were true- a low frequency of embryo formation but high germination rate of developed embryos. For lack of better understanding, we currently optimize ovule culture conditions for maximum embryo development only. Germination and plant development are encouraged in subsequent culture steps.

\section{Parentage of plants from ovule culture}

Although it has been assumed that plants from ovule culture are hybrids, the occasional development of polyembryos (Emershad and Ramming, 1984; Emershad et al., 1989) and embryos growing from the ovule surface (D.J.G. personal observation) suggest that some plants arise somatically. Additionally, it is necessary to confirm genetic origin to exclude the possibility of self-fertilization, given low plant recovery rates from crosses using seedless maternal parents.

Leaf extracts from several parents and their progeny were subjected to starch gel electrophoresis and stained for glucosephosphate isomerase (GPI). Polymorphism of GPI in grape is conditioned by a single locus, Gpi-c with three alleles designated S, M, and F (Durham et al., 1989; Loukas et al., 1983; Weeden et al., 1988). Homozygous plants exhibit a single band, whereas heterozygotes have three bands, resulting from two allelic bands and an interallelic heterodimer. Comparing the distribution of S, M, and F bands between parent and progeny demonstrated that $67 \%$ of progeny from four crosses were clearly hybrid, having band combinations different from the female parent and consistent with expected hybrid combinations. Another 21 ' $\% 0$ had isozyme patterns that could have arisen by either selfing or crossing. Only $12 \%$ of the progeny were clearly not hybrids and were most likely self-pollinations, although the possibility that some arose by somatic embryogenesis cannot be ruled out. Therefore, at least $67 \%$ and as many as $88 \%$ of the progeny were of hybrid origin.

\section{Field performance}

Ovule culture-derived plants have been established in vineyard progeny tests since 1986 (Fig. 1H). Four out of 190 plants produced fruit in 1988 and two of these were seedless, with smaller seed traces than either parent. For comparison, conventional breeding methods using seeded females and pollen from seedless cultivars yield only $10 \%$ to $15 \%$ seedless progeny (Loomis and Weinberger, 1979).

As ovule culture becomes increasingly integrated into our seedless grape breeding program, ongoing research seeks to in- crease ovule culture efficiency by shortening the period from pollination to plant recovery and increasing plant recovery rates.

\section{Literature Cited}

Cain, D. W., R.L. Emershad, and R.E. Tarailo. 1983. In-ovulo embryo culture and seedling development of seeded and seedless grapes (Vitis vinifera L.). Vitis 22:9-14.

Chaparro, J, X., R.G. Goldy, B.D. Mowrey, and D.J. Werner. 1989. Identification of Vitis vinifera L. $\times$ Muscadinia rotundifolia small hybrids by starch gel electrophoresis. HortScience 24:128-130.

Durham, R. E., G.A. Moore, D.J. Gray, and J.A. Mortensen. 1989. The use of leaf GPI and IDH isozymes to examine the origin of polyembryony in cultured ovules of seedless grape. Plant Cell Rpt. 7:669-672.

Emershad, R.L. and D. W. Ramming. 1984. In-ovulo embryo culture of Vitis vinifera L. cv. Thompson Seedless. Amer. J. Bet. 71:873877 .

Emershad, R. L., D.W. Ramming, and M.D. Serpe. 1989. In ovulo embryo development and plant formation from stenospermic genotypes of Vitis vinifera. Amer. J. Bet. 76:397-402.

Fisher, K.H. and O.A. Bradt. 1985. 'Vanessa' grape. HortScience 20:147-148.

Flemion, F. 1937. After ripening at $5^{\circ} \mathrm{C}$ favours germination of grape seeds. Contr. Boyce Thompson Inst, 9:7-15.

Goldy, R.G. and U. Amborn. 1987. In vitro culturability of ovules from 10 seedless grape clones. HortScience 22:952.

Gray, D. J., L.C, Fisher, and J.A. Mortensen. 1987. Comparison of methodologies for in ovulo embryo rescue of seedless grapes. HortScience 22:1334-1335.

Gray, D.J. and J.A. Mortensen. 1987. Initiation and maintenance of long term somatic embryogenesis from anthers and ovaries of Vitis longii 'Microsperma'. Plant Cell Tissue \& Organ Culture 9:73-80.

Loomis, N.H. and J.H. Weinberger. 1979. Inheritance studies of seedlessness in grapes. J. Amer. Soc. Hort. Sci. 104:181-184.

Loukas, M., M.N. Stavrakakis, and C.B. Krimbas. 1983. Inheritance of polymorphic isoenzymes in grape cultivars. J. Hered. 74:181183.

Moore, J.N. 1983. 'Reliance' seedless grape. HortScience 18:963964.

Moore, J.N. 1985. 'Mars' seedless grape. HortScience 20:313.

Moore, J.N. and E. Brown. 1977. 'Venus' grape. HortScience 12:585.

Mortensen, J.A. and D.J. Gray. 1987. 'Orlando Seedless' grape. HortScience 22:327-328.

Murashige, T. and F.M. Skoog. 1962. A revised medium for rapid growth and bioassays with tobacco tissue cultures. Physiol. Plant. 15:473-497.

Nitsch, J.P. and C. Nitsch. 1969. Haploid plants from pollen grains. Science 163:85-87.

Olmo, H.P. 1936. Choice of parent as influencing seed germination in fruits. Proc. Amer. Soc. Hort. Sci. 41:171-175.

Pool, R. M., G.W. Remaily, B.I. Reisch, J.P. Watson, and K.H. Kimball. 1981. 'Remaily Seedless' grape. HortScience 16:232-233.

Pool, R. M., J.P. Watson, K.H. Kimball, and J. Einset. 1977. 'Canadice' grape. HortScience 12:586.

Pratt, C. 1971. Reproductive anatomy in cultivated grapes-A review. Amer. J. Enol Vitic. 22:92-109.

Reisch, B. I., G.W. Remaily, R.M. Pool, and J.P. Watson. 1986. 'Einset Seedless' grape. HortScience 21:155-156.

SAS Institute, Inc. 1985. SAS user's guide: Statistics. version 5. SAS Inst., Cary, N.C.

Spiegel-Roy, P., N. Sahar, J. Baron, and U. Lavi. 1985. In vitro culture and plant formation from grape cultivars with abortive ovules and seeds. J. Amer. Soc. Hort. Sci. 110:109-112,

Stout, A.B. 1936. Breeding for hardy seedless grapes. Proc. Amer. Soc. Hort. Sci. 34:416-420.

Weeden, N. F., B.I. Reisch, and M.-H.E. Martens. 1988. Genetic analysis of isozyme polyorphism in grape. J. Amer. Soc. Hort. Sci. 113:765-769. 